УДК 81'42: 82-84

DOI https://doi.org/10.26661/2414-9594-2021-1-20

\title{
КАТЕГОРИЧНІСТЬ ЯК ЗАСІБ РЕАЛІЗАЦІЇ АВТОРИТЕТНОСТІ ІНТЕРНЕТ-АФОРИЗМУ: ПОСТАНОВКА ПРОБЛЕМИ
}

\author{
Машкіна О. М. \\ кандидат філологічних наук, \\ доиент кафедри загального мовознавства і германістики \\ факультету іноземної філологіi \\ Національний педагогічний університет імені М. П. Драгоманова \\ вул. Пирогова, 9, Київ, Україна \\ orcid.org/0000-0002-7849-0535 \\ sakenael@gmail.com
}

\author{
Ключові слова: афоризм, \\ класичний афоризм, \\ інтернет-афоризм, \\ конвергентна культура, \\ культура співучасті, \\ авторитетність, \\ категоричність.
}

Статтю присвячено дослідженню проблеми реалізації авторитетності інтернет-афоризму. У роботі інтернет-афоризм розглядається як складова частина сучасної конвергентної культури, тобто «культури співучасті», яка передбачає високу активність реципієнтів інформації, на відміну від культури старих медіа. Досягнення такої активності забезпечується технічними можливостями сучасних медіа, наприклад, у соціальних мережах, можливістю учасників інтернет-комунікації реагувати на отриману інформацію: ставити позначку «подобається», залишати коментарі, ділитися матеріалом. Під впливом сучасної віртуальної культури відбуваються істотні соціокультурні трансформації, які детермінують зміни в жанровій системі: частина жанрів переміщується у віртуальний простір або дублюється в ньому, спостерігаються зміни в самих жанрах. Афоризм характеризується високим рівнем авторитетності та відтворюваності. У роботі розрізняються класичний афоризм та інтернет-афоризм, який має характерні унікальні ознаки, як-от інтерактивність, зумовлена існуванням у віртуальному середовищі. Активна роль реципієнтів інтернет-афоризму та вплив на його відтворюваність підвищують цінність уваги сторони, яка сприймає, та робить цю увагу своєрідним капіталом. Увага реципієнтів інформації, у свою чергу, напряму пов'язана з поняттям іiі авторитетності. Жанрова форма афоризму розглядається як прецедентна жанрова форма та передбачає високий рівень авторитетності висловлювання, отже, високий рівень довіри. Інтернет-афоризм, використовуючи прецедентну жанрову форму, підвищує авторитетність інформації. Категорія категоричності, яку в роботі розглянуто у взаємозв'язку з поняттям достовірності, виступає засобом підвищення авторитетності висловлювання. У російськомовних інтернет-афоризмах категоричність виражається за допомогою багатократних заперечень, імперативних конструкцій, двоскладової форми побудови інтернет-афоризму у вигляді складнопідрядного речення з умовним підрядним реченням у складі тощо. У статті робиться висновок про особливе значення авторитетності для інтернетафоризму та іiі важливість у перцепції закладеної в ньому інформації. Категорія авторитетності інтернет-афоризму реалізується за допомогою прецедентної жанрової форми та мовних засобів висловлювання. 


\title{
CATEGORICALNESS AS A MEANS OF REALIZATION \\ OF THE INTERNET APHORISM AUTHORITATIVENESS: PROBLEM STATEMENT
}

\author{
Mashkina O. M. \\ Candidate of Philological Sciences, \\ Associate Professor at General Linguistics and Germanistics Department \\ of the Faculty of Foreign Philology \\ National Pedagogical Dragomanov University \\ Pyrohova str., 9, Kyiv, Ukraine \\ orcid.org/0000-0002-7849-0535 \\ sakenael@gmail.com
}

Key words: aphorism, classical aphorism, Internet aphorism, convergent culture, culture of complicity, authority, categorical.

\begin{abstract}
The article is devoted to the study of the Internet aphorism authoritativeness realization. Internet aphorism is regarded as a component of modern convergent culture, that is, "participatory culture", which provides high activity of recipients of information in contrast to the culture of the old media. Such activity is provided by the technical capabilities of modern media, for example, in social networks, in particular the possibility of Internet communication participants to respond to the information received: to give "Like", leave comments, share the content. The article states that significant socio-cultural transformations take place in the wake of the influence of modern virtual culture, that determines changes in the genre system: partly genres move to the Web, or duplicated in it. There are also changes in the genres themselves. Aphorism is a brief statement that has a high level of authoritativeness and repeatability. The classic aphorism and Internet aphorism are differentiated in the paper, Internet aphorism is characterized by unique features, in particular its interactivity due to its existence in a virtual environment. The active role of recipients of Internet aphorism and influence on its repeatability, increases the value of the addressee's attention and turns it into a sort of capital. Attention of the information recipients, in turn, is directly related to the notion of its authoritativeness. The genre form of aphorism, which in this article is considered as a precedent genre form, provides a high level of statement authoritativeness and, accordingly, a high-level credibility of information concluded in it. Internet aphorism is often a statement that has a high level of categoricalness. The category of categoricalness, which in the work is considered to be in a relationship with the concept of reliability, is regarded as a means of increasing the authoritativeness of the statement. In Russian Internet aphorisms, categoricalness is expressed by multiple objections, imperative structures, a two-component form of the Internet aphorism, in the form of a complex sentence with a conditional subordinate sentence, etc. The article concludes that the most authoritativeness importance for Internet aphorism and its decisive value in the perception of information laid down in it. The category of authoritativeness in the Internet aphorism is realized through the precedent genre form and language means.
\end{abstract}

Постановка проблеми. У сучасному світі інтернет, «майже відчутна і явна ознака глобалізаціï» [5, с. 36], визначає або має суттєвий вплив на всі аспекти людського життя. Віртуальне середовище багато в чому визначає культуру людського суспільства: під впливом Мережі змінюються культурні настанови, трансформуються класичні культурні форми. Спостерігається поступове переміщення або дублювання класичних літературних жанрів у віртуальне середовище. Розміщення в інтернеті детермінує не тільки доступність інформації для читача, а й змінює сам перцептивний процес, забезпечує зворотний зв'язок. В умовах інтенсифікації інформаційного потоку особливої популярності набувають короткі жанрові форми, як-от афоризм. Існування афоризму у віртуальному середовищі наділяє його унікальним набором характеристик і впливає на його перцепцію. 
Вивчення особливостей існування жанрів, їхніх трансформацій у віртуальному середовищі, зокрема жанру афоризму, дослідження перцептивних процесів споживачів інформації, зокрема й проблема авторитетності інформації в інтернеті, $\epsilon$ важливими завданнями для сучасної лінгвістики, що робить дане дослідження актуальним і перспективним.

Дослідники виділяють різні види афоризмів, наприклад, Н.Б. Мечковська пише про класичні афоризми, які визначає як «узагальнені істини», контекстуально незалежні (самодостатні), лаконічні і «досконалі» у художньо-естетичному плані [6, с. 79], афоризми другого покоління, афоризми нового часу [6]. Трансформація жанрової форми афоризму привела до появи такої його варіації, як інтернет-афоризм. У нашій роботі для розмежування понять пропонуються терміни «класичний афоризм» та «інтернет-афоризм», де інтернет-афоризм - це короткий вислів, що має форму афоризму, який функціонує у віртуальному середовищі.

Інтернет-афоризм передбачає зворотний зв'язок, на відміну від класичного афоризму, реакція на який переважно виражається в усній формі, тоді як реакція на інтернет-афоризм виражається в письмовій формі і в кількості позначень «подобається», що визначає його інтерактивний характер. Варто зазначити, що важливим аспектом інтернет-афоризму, крім його інтерактивності, $є$ його зумовленість сучасним віртуальним середовищем: інтернет-афоризм можна розглядати як явище сучасної «культури співучасті», конвергентної культури, яка може бути протиставлена пасивному медіасприйняттю. Г. Дженкінс розуміє під конвергенцією «технологічні, індустріальні, культурні та соціальні трансформації способів поширення медіа в нашій культурі» [2, с. 25], підкреслює, що «конвергенція реалізується насамперед в умах окремих користувачів, а також через їхню соціальну взаємодію з іншими користувачами» [2, с. 30], розділяючи медіа на активні, тобто такі, «у яких користувачі шукають інформацію», та пасивні, «у яких користувач пасивно споживає контент» [2, с. 32]. Отже, «Мережа пропонує більш спеціалізовані канали іiі [культури] поширення, будучи, по суті, реакцією на цю культуру» [2, с. 296]. Характерною особливістю такої культури $\epsilon$ «винос» назовні і поширення того, що було приховано раніше, наприклад ведення щоденника в Мережі: якщо в доінтернетну епоху щоденникові записи замикалися переважно на автора і не передбачали публічності, за винятком, можливо, щоденників відомих особистостей, то сьогодні інтернет дає можливість такої слави всім, хто має доступ, робить внутрішні розумові процеси доступними для інших: «<...> технології нових медіа сприяють екстерналізації й об'єктивації мислення, а також нарощують потенціал контр- олю за останнім» [5, с. 95]. На думку Н.Б. Мечковської, єдиною обов'язковою ознакою афоризму $є$ його відтворюваність [6, с. 78]. Інтернет-афоризм створюється саме 3 метою бути відтворюваним. Інтернет-афоризми, 3 огляду на їхній узагальнювальний характер, можна розглядати і як висловлювання, що генералізують, «фрази, у яких підсумовується накопичений загальнолюдський досвід, досвід якого-небудь соціуму або ж життєвий досвід якоїсь окремої персони» [8, с. 61]. Особливостями таких висловлювань $\epsilon$ те, що вони «легко запам'ятовуються, врізаються в пам'ять, багато - завдяки своїй несподіваності, парадоксальності» [8, с. 62]. Інтернет-афоризм створюється у формі висловлювань, що генералізують, із прицілом на запам'ятовуваність, i, як наслідок, відтворюваність. Отже, інтернет-афоризм відрізняється від афоризму у класичному розумінні існуванням у принципово іншому комунікативному середовищі, яке передбачає активність реципієнта: останній може не тільки висловлювати свою реакцію (відмітками «подобається», коментарями), але й, що особливо важливо, може поширювати інтернет-афоризми, збільшувати аудиторію реципієнтів.

Важливо відзначити і те, що збільшення інформації сприяє також підвищенню конкуренції за людську увагу: публікація в інтернеті будь-якого контенту не має сенсу, якщо його ніхто не бачить, не читає і не реагує на нього; iii короткостроковість: постійна поява нової інформації сприяє іiі швидкому забуванню, отже, скороченню ії життєвого циклу; їі знецінення: цінність того, що є короткостроковим, швидко і просто замінюваним, неминуче падає.

У статті розглядаються особливості інтернет-афоризму як трансформованого класичного афоризму в контексті вивчення характерних особливостей функціонування жанрів у просторі Мережі, особливості взаємозв'язку інтернет-афоризму і поняття авторитетності.

Мета статті - розглянути інтернет-афоризм як трансформований класичний афоризм у контексті понять авторитетності та категоричності, визначити способи підвищення авторитетності інтернет-афоризму й основні засоби реалізації категоричності.

Методологія дослідження. Аналіз останніх наукових праць дозволив окреслити способи реалізації авторитетності інтернет-афоризму та вказати на зв'язок понять авторитетності та категоричності. За допомогою методу суцільної вибірки зі сторінок, де публікуються інтернетафоризми (використовувалися сторінки платформи Facebook), було дібрано 237 афоризмів. Аналіз вибірки дозволив виділити основні засоби реалізації категоричності в інтернет-афоризмах.

Виклад основного матеріалу дослідження. За визначенням Є.Є. Іванова, «афоризми у своєму 
найбільш поширеному розумінні - це жанр літературних висловів як окремих літературно-художніх і публіцистичних творів, а також філософських творів (переважно морально-етичного змісту)» $[3$, с. 10]. Зв'язок афоризмів із філософією відзначається також у праці "A theory of the aphorism. From Confucius to Twitter" [11, с. 7]. До жанрових особливостей афоризму належать, серед іншого, його «світоглядна глибина і значущість» [3, с. 10].

3 появою нових медіа класичний афоризм, який переходить у віртуальне середовище, зазнає змін, зокрема й через зміни каналів передачі. Істотну роль у появі такої жанрової форми, як інтернет-афоризм, відіграють і трансформації, що відбуваються 3 аудиторією, наприклад екстерналізація внутрішніх розумових процесів, оскільки «те, що раніше належало сфері особистого і вважалося унікальним індивідуальним станом або ментальним процесом, зараз переживає своє втілення в публічній сфері» [5, с. 95].

Становлення і розвиток нових медіа змінюють сприйняття жанрових форм: на думку Н.Л. Лейдерманна, «у перехідні епохи, які утворюються на місці розриву культурних ер <..>, коли набуває широкого поширення міфологія хаосу, відбувається руйнування раніше авторитетних жанрів, проголошується відмова від жанрових канонів, сама категорія жанру дискредитується, оголошується теоретичної фікцією» [4, с. 153]. Криза авторитетності класичного афоризму сприяє становленню інтернет-афоризму. Н.Л. Лейдерман також вказує на появу антижанрів, однак зазначає, що «антижанри тому-то і мають естетичну семантику, що орієнтовані на пам'ять осміюваного або пародійованого жанру, тільки перевертають іiі навиворіт» $[4$, с. 156]. Деякою мірою інтернет-афоризм $\epsilon$ таким антижанром, який, однак, спирається на прецедентну форму класичного афоризму. Як «використання прецедентного тексту в оригінальному вигляді дозволяє актуалізувати закладені в ньому емоції $<\ldots>$, уводить текст у прецедентний соціокультурний контекст» [10, с. 101], так і прецедентний жанр актуалізує знання про нього людини, яка сприймає, готує подальше сприйняття. Отже, 3 налаштуванням того, хто сприймає, на певні характеристики висловлювання (серйозність, мудрість, авторитетність), знижується критичність сприйняття самого сенсу інтернет-афоризму.

Також відзначимо, що в сучасному мережевому просторі спостерігаються дві протилежні тенденції: $з$ одного боку, афоризм втрачає свою авторитетність, з іншого боку, має місце використання афористичній форми для додавання висловленню авторитетності. У такому разі «авторитетною стає сама по собі мовна форма, яка імпліцитно впливає на свідомість адресата повідомлення й обумовлює фідеїстичне сприйняття інформації, закладеної у висловлюванні, що генералізує» [8, с. 60]. Вихолощення афоризму класичного змінилося прагненням використовувати афористичну форму для маніпулювання сприйняттям користувачів, оскільки в інтернет-афоризмах «серйозній» формі афоризму не завжди відповідає зміст, отже, основний принцип інтернет-афоризму - це відповідність насамперед зовнішній формі, а не внутрішній.

Використання прецедентної форми класичного афоризму покликане впливати на сприйняття інтернет-афоризму реципієнтами, підвищувати його авторитетність, оскільки така форма «імпліцитно діє на свідомість адресата повідомлення і стає сигналом того, що смислу висловлювання можна довіряти» [8, с. 66]. На думку Н.I. Сухорукової, «якщо розуміти комунікацію як процес взаємної координації діяльності за посередництвом вербальних і невербальних знакових систем, що виробляються і змінюються в самому цьому процесі, будь-яке висловлювання, будь-який фрагмент дискурсивного процесу, таким чином, має певну вартість на ринку лінгвістичних дій» [9, с. 29].

Авторитетність інформації в інтернеті безпосередньо пов'язана 3 його популярністю і відтворюваністю, тобто, оскільки вона здатна привертати увагу, авторитетність підвищує увагу користувачів, їхню увагу завжди можна монетизувати, наприклад за допомогою реклами, отже, у Мережі «авторитет є формою символічного капіталу» [9, с. 29-30]. Підвищення рівня відтворюваності інтернет-афоризму $є$ водночас способом посилення його авторитетності, оскільки «авторитетність прислів'я і будь-якого іншого постійно відтвореного в промові анонімного тексту (тексту із «забутим автором») також $є$ персональною; вона знайдена в результаті регулярного вживання заданої мовної одиниці, визнання іiї мудрості та значущості носіями мови» $[8$, с. 65]. Дослідники відзначають, що «авторитет виникає не відразу, але знаходиться в результаті функціонування певної особи, твори, реалії тощо. У соціальному і культурному просторі в синхронії і діахронії» $[8$, с. 65]. Засобами посилення авторитетності висловлювання можуть бути авторитетність його автора, власне мовні засоби, семантика узагальненості і сама мовна форма [8]. Відмітною особливістю авторитету інтернет-афоризму є те, що він спирається на авторитетність жанрової форми класичного афоризму.

Одним зі способів підвищення авторитетності інтернет-афоризму є його категоричність, яка може свідчити «про цілковиту переконаність, упевненість автора тексту у своїй правоті» [7, с. 48] або сприйматися так реципієнтом. С.Г. Андреєва пов'язує категорію категоричності з поняттям ієрархії, оскільки «категоричність висловлювання також виявляється в цьому контексті свого роду соціальним 
знаком, що розрізняють як різні культури, так i представники однієї культури, що мають різне положення в соціальній ієрархії» [1, с. 242]. Категоричність афоризму в підсвідомості реципієнта «вкладає» наявну в ньому інформацію в уста більш високопоставленого автора, що автоматично підвищує його авторитетність і викликає більш довірче iii сприйняття. Крім того, категоричність висловлювання пов'язана 3 поняттям його достовірності, категоричність «взаємодіє 3 категорією персуазивності» [1, с. 244], «за допомогою якої мовець кваліфікує повідомлення 3 погляду його достовірності» [1, с. 243], хоча варто підкреслити, що «категоричним може бути не тільки достовірне, але і недостовірне висловлювання» [1, с. 244].

Аналіз відібраних із сайтів афоризмів свідчить про те, що для російськомовних інтернет-афоризмів характерні такі основні засоби вираження категоричності: використання одразу декількох заперечень в одному висловлюванні:

Никому никогда ничего не объясняйте - каждый все равно поймет так, как ему выгодно [13].

Никогда никому ничего не доказывайте. Это вама жизнь, а не теорема по геометрии [13].

Никто ни за кем не должен бегать. Люди должны бежсать только навстречу друг другу [12].

Никогда не отрекайся от своего внутреннего зверя. Однажды твоя человечность сломается там, где он даст тебе силь выжить [12].

Никогда никому не мстите. Все будет. У васхорошо. А у них - как заслужили [14].

Слугувати реалізації категоричності інтернет-афоризму може з'ясувальне складнопідрядне речення: если $<\ldots>$, то $<\ldots>$, если $<\ldots>$, значит $<\ldots>$, если $<\ldots>$ :

Если человек прекратил спор, то не факт, что вы правы. Возможно, он понял, что вы тупой [13].

Если без вас можно прожить хотя бы один день, не узнав, как ваши дела и что с вами, - значит, они могут прожить без вас и все остальнье дни [13].

Если человек заинтересован в тебе, он всегда найдет способ узнать: где тыл? как тыл? Все остальное просто отговорки [13].

Категоричність може бути реалізована вживанням прислівників із семантикою виключності: только, только тогда:

Только имеюшие детей понимают, что есть жизнь, которая дороже собственной [13].
Тебя ценят только тогда, когда в тебе нуждаются. Такова жизнь [13].

Категоричність реалізується також використанням імперативних форм:

Забудь то, что в прошлом ранило тебя, но никогда не забывай, чему это тебя научило [13].

Очнитесь. Никто нас не любит такими, какие мы есть. Это коварное вранье. Нас любят красивыми, весельми, жизнерадостными и ухоженнылми [13].

Часто імператив доповнюється лексемами iз семантикою безапеляційності, наприклад: никто, никогда.

Помните, не получить желаемого - это иногда и есть везение [13].

Категоричність може посилюватися також за допомогою різних типів повторів, наприклад повторів окремих слів, синтаксичних структур, дериваційних повторів тощо:

Развод - это не трагедия. Трагедия - это оставаться в несчастливом браке и учить неправильно видеть любовь [13].

Забудь то, что в прошлом ранило тебя, но никогда не забывай, чему это тебя научило [13].

Мужчина, не умеющий держать слово, ни одну женшину не удержит [13].

Висновки і перспективи подальших досліджень. Отже, поняття авторитетності є одним із центральних у вивченні жанрової форми інтернет-афоризму. Авторитетність афоризму у віртуальному середовищі безпосередньо пов'язана 3 категоріями персуазивності та категоричності, має вирішальне значення для його сприйняття реципієнтами. Категоричність в інтернет-афоризмах реалізується як використанням авторитетності жанрової форми класичного афоризму, а також мовними засобами. Основними засобами вираження категоричності в російськомовних афоризмах є: використання різних типів повторів, множинних заперечень, імперативних форм, з'ясувальних складнопідрядних речень, розбиття висловлювання на короткі прості речення, останнє 3 яких містить несподівану кінцівку, прислівників iз семантикою виключності, винятковості.

Перспективами майбутніх досліджень може бути порівняльне вивчення засобів підвищення авторитетності інтернет-афоризмів та інших малоформатних текстів.

\section{ЛІТЕРАТУРА}

1. Андреева Е.Г. Язык и культура: категоричность высказывания как отражение социокультурных норм в языковых моделях. Вестник Русской христианской гуманитарной академии. Москва, 2008. № 1. T. 9. С. 242-251.

2. Дженкинс Г. Конвергентная культура. Столкновение старых и новых медиа. Пер. с англ. А.В. Гасилина. Москва : Группа компаний «РИПОЛ классик», 2019. 384 с.

3. Иванов Е.Е. Лингвистика афоризма : учебно-методическое пособие. Могилев : МГУ имени А.А. Кулешова, 2016. 
4. Лейдерман Н.Л. Проблема жанра в модернизме и авангарде (Испытание жанра или испытание жанром). Studi Slavistici. 2008. № 5 (1). С. 147 Пер. с англ. А. Гасилина 177.

5. Манович Л.З. Язык новых медиа. Москва : АД «Маргинем пресс», 2018. 400 с.

6. Мечковская Н.Б. Жанры афористики и градация высказываний по степени идиоматичности. Жанры речи. Саратов : Издательский центр «Наука», 2009. Вып. 6. С. 79-111.

7. Руженцева Н.Б. Дискредитирующие тактики и приемы в российском политическом дискурсе : монография. Екатеринбург : Урал. гос. пед. ун-т. 2004. С. 294

8. Суздальцева В.Н. Генерализующие высказывания как средство манипулирования сознанием массового адресата. Медиалингвистика. 2018. Т. 5. № 1. С. 60-72.

9. Сухорукова Н.И. Прямолинейность и категоричность высказывания как проявление коммуникативной категории авторитетности (на материале аутентичных англоязычных финансово-аналитических комментариев). Язык, сознание, коммуникация : сборник статей / отв. ред. В.В. Красных, А.И. Изотов. Москва : Макс-Пресс, 2011. Вып. 43. С. 28-37.

10. Языковое сознание жителей Воронежа / И.А. Стернин и др. ; под ред. И.А. Стернина. Воронеж : Истоки, 2010. $250 \mathrm{c.}$

11. Hui A. A theory of the aphorism. From Confucius to Twitter. Princeton and Oxford : Princeton university press, 2019. $273 \mathrm{p}$.

12. Группа «Мудрость». URL: https://www.facebook.com/groups/850718721951771/?epa=SEARCH_BOX (дата звернення: 06.04.2021).

13. Группа «Мудрость Wisdom”. URL: https://www.facebook.com/groups/1871888156256472/ (дата звернення: 06.04.2021).

14. Группа «Умные мысли / цитаты». URL: https://www.facebook.com/thoughts.smart/ (дата звернення: 06.04.2021).

\section{REFERENCES}

1. Andreeva E.G. (2008) Yazyk i kul'tura: kategorichnost' vyskazyvaniya kak otrazhenie sotsiokul'turnykh norm v yazykovykh modelyakh. Bulletin of the Russian Christian Humanitarian Academy. Moscow. № 1. Vol. 9. P. 242-251.

2. Dzhenkins G. (2019) Konvergentnaya kul'tura. Stolknovenie starikh i novikh media / transl. from Eng.by A. Gasilina]. Moskva: Company group "RIPOL klassik". 384 p.

3. Ivanov E.E. (2016) Lingvistika aforizma: uchebnometodicheskoe posobie. [Electronic resource]. Mogilev : MSU A.A. Kuleshova.

4. Leiderman N.L. (2008) Problema zhanra v modernizme i avangarde (Ispytanie zhanra ili ispytanie zhanrom). Studi Slavistici, 5 (1), 2008. S. 147-177.

5. Manovich L. (2018) Yazyk novykh media. Moskva: AD Marginem press, 2018. 400 p.

6. Mechkovskaya N.B. (2009) Zhanry aforistiki i gradatsiya vyskazyvanii po stepeni idiomatichnosti. Zhanry rechi. Saratov: Press cenre "Nauka". Issue 6. P. 79-111.

7. Ruzhentseva N.B. (2004) Diskreditiruyushchie taktiki i priemy v rossiiskom politicheskom diskurse: Monografiya. Ekaterinburg: Ural State Pedagogical University. 294 p.

8. Suzdal'tseva V.N. (2018) Generalizuyushchie vyskazyvaniya kak sredstvo manipulirovaniya soznaniem massovogo adresata. Medialingvistika. Vol. 5. № 1. P. 60-72.

9. Sukhorukova N.I. (2011) Pryamolineinost' i kategorichnost' vyskazyvaniya kak proyavlenie kommunikativnoi kategorii avtoritetnosti (na materiale autentichnykh angloyazychnykh finansovoanaliticheskikh kommentariev). Yazyk, soznanie, kommunikatsiya: Sb. statei / Otv. red. V.V. Krasnykh, A.I. Izotov. Moskva: MAKS Press, Issue 43. P. 28-37.

10. Yazykovoe soznanie zhitelei Voronezha (2010) / I.A. Sternin [and collegues] / [under the editorship of I.A. Sternin]. Voronezh: Istoki, 2010. 250 p.

11. Hui A. (2019) A theory of the aphorism. From Confucius to Twitter. Princeton and Oxford: Princeton university press. $273 \mathrm{p}$.

12. Group "Mudrost"”. https://www.facebook.com/groups/850718721951771/?epa=SEARCH_BOX (date of request 6.04.2021)

13. Group "Mudrost' Wisdom". https://www.facebook.com/groups/1871888156256472/ (date of request 6.04.2021)

14. Group "Umnye mysli / tsitaty". https://www.facebook.com/thoughts.smart/ (date of request 6.04.2021) 